\title{
Neurological findings in pediatric penetrating head injury at a university teaching hospital in Durban, South Africa: a 23-year retrospective study
}

\author{
Kadhaya David Muballe, MD, ${ }^{1}$ Timothy Hardcastle, MMed, PhD, ${ }^{2}$ and Erastus Kiratu, MBChB ${ }^{1}$ \\ Department of ${ }^{1}$ Neurosurgery and ${ }^{2}$ Trauma Surgery, Inkosi Albert Luthuli Central Hospital and University of KwaZulu-Natal, \\ Durban, KwaZulu-Natal, South Africa
}

\begin{abstract}
OBJECTIVES Penetrating traumatic brain injuries (TBIs) can be divided into gunshot wounds or stab wounds based on the mechanisms of injury. Pediatric penetrating TBIs are of major concern as many parental and social factors may be involved in the causation. The authors describe the penetrating cranial injuries in pediatric patient subgroups at risk and presenting to the Department of Neurosurgery at the University of KwaZulu-Natal, by assessment of the Glasgow Coma Scale (GCS) score and review of the common neurological manifestations including cranial nerve abnormalities.
\end{abstract}

METHODS The authors performed a retrospective chart review of children who presented with penetrating TBIs between 1985 and 2007 at a university teaching hospital. Descriptive statistical analysis with univariate and multivariate logistic regression was used to assess the variables.

RESULTS Out of 223 children aged 16 years and younger with penetrating TBls seen during the study period, stab wounds were causal in $127(57 \%)$ of the patients, while gunshot injuries were causal in $96(43 \%)$. Eighty-four percent of the patients were male. Apart from abnormal GCS scores, other neurological abnormalities were noted in 109 (48.9\%) of the patients, the most common being cranial nerve deficits $(22.4 \%)$ and hemiparesis. There was a strong correlation between left-sided stab wounds and development of seizures. The mean age of patients with neurological abnormalities was 11.72 years whereas that of patients with no neurological abnormalities was 8.96 years.

CONCLUSIONS Penetrating head injuries in children are not as uncommon as previously thought. There was no correlation between the age group of the patients and the mechanism of injury, which implies that stab or gunshot injuries could occur in any of our pediatric population with the same frequency. While gunshot injuries accounted for $56 \%$ of the patient population, stab injuries still accounted for $44 \%$.

Following penetrating head injuries, neurological abnormalities tend to occur in the older subgroup of the pediatric patients. The most common neurological abnormalities were hemiparesis followed by cranial nerve deficits. Facial nerve deficits were the most commonly seen cranial nerve abnormality. Immediate convulsions were a significant feature in patients with stab injuries to the head compared to those with gunshot injuries.

http://thejns.org/doi/abs/10.3171/2016.5.PEDS167

KEY WORDS penetrating traumatic brain injury; gunshot; head; stab wound; neurological sequelae; trauma

$\mathrm{T}$ HE magnitude, management, sequelae, and contributing factors associated with penetrating head injuries are well established in the literature.,16 Penetrating traumatic brain injuries (TBIs) are common in war; however, low-velocity penetrating pediatric TBIs in situations other than war are uncommon and are said to have a better prognosis when treated. ${ }^{3}$ Various causes of penetrating head injuries include pens, nails, needles, table knives, forks, scissors and other instruments ${ }^{6}$

A cranial stab wound is usually caused by a weapon with a small impact area, and it often produces a slot skull fracture with an underlying tract hematoma. ${ }^{7}$ Aggressive debridement of penetrating missile injuries has been the accepted mode of management, but it is not necessarily 
the rule in the current neurosurgical practice, especially in a civilian population. ${ }^{5,7}$ In penetrating brain injuries, CSF fistulas may occur in $0.63 \%-8.9 \%$ of cases among patients who have sustained missile injuries in war situations. ${ }^{13}$

A review of the local experience with pediatric penetrating TBIs in Durban, one of the major cities in South Africa, was lacking. In this study we determined the common neurological manifestations, subgroups at risk, and presenting Glasgow Coma Scale (GCS) scores among children with penetrating head injury.

\section{Methods}

This was a retrospective chart review of medical records and imaging studies of pediatric patients who had sustained a penetrating TBI who were admitted to and managed at the Department of Neurological Surgery at Inkosi Albert Luthuli Central Hospital, University of KwaZuluNatal (a national quaternary care hospital and Level 1 trauma center). The records evaluated were of patients admitted between January 1985 and December 2007. Charts were reviewed for injury patterns, risk groups, neurological sequelae, and presenting physiological parameters, including GCS score. Ethical approval was obtained from the University of KwaZulu-Natal and the KwaZulu-Natal Department of Health, including a waiver of individual consent, as this was a chart review. Statistical analysis was performed using the chi-square and Fisher tests and with regression analysis. A statistically significant difference between the events was defined as a $\mathrm{p}<0.05$.

\section{Results \\ Overview}

Over the period from January 1985 to December 2007, 18,982 patients with head injury were admitted to the neurological surgery service. Of these, 3020 were children under 16 years of age. Two hundred twenty-three children with penetrating head injuries were identified. These injuries resulted from either a gunshot or stab injury and constituted $7.4 \%$ of all pediatric neurotrauma admissions and $1.2 \%$ of all TBI patients admitted to the only public neurosurgical department in KwaZulu-Natal.

\section{Age, Sex, Mechanism of Injury, and Duration of Hospital Stay}

The patients were categorized into the following age groups: $0-2,3-12$, and $13-16$ years (Table 1). Of the 223 patients admitted with penetrating TBIs, 31 (13.9\%) were in the $0-2$ age group, $83(37.2 \%)$ were in the 3-12 age group, and 109 (48.9\%) were in the 13-16 age group. The mean age was 10.3 years and the median age was 12 years; $75 \%$ of the patients were males aged 3-16 years (Table 1 ).

One hundred eighty-nine $(84.8 \%)$ of the patients with penetrating TBI were males. In 127 (57\%) of the patients, the TBI was caused by a gunshot, while in $96(43 \%)$ it was caused by stabbing, a difference that is not statistically significant (Table 2). There was also no statistically significant relationship between age and mechanism of injury (chi-square test $3.011, \mathrm{p}=0.222$ ) (Table 2). The
TABLE 1. Age distribution*

\begin{tabular}{ccc}
\hline Age Range in Yrs & Frequency & Percentage \\
\hline $0-2$ & 31 & 13.9 \\
\hline $3-12$ & 83 & 37.2 \\
\hline $13-16$ & 109 & 48.9 \\
\hline Total & 223 & 100 \\
\hline
\end{tabular}

* The mean age 10.3 years; $48.9 \%$ of the patients were $13-16$ years, and $70 \%$ of the patients were males aged $13-16$ years.

mean duration of hospitalization was 8.3 days for $70 \%$ of patients, and for $5.5 \%$ of the patients hospitalization was prolonged.

\section{Neurological Sequelae Overview}

The number of patients who presented with neurological sequelae was 109 (48.9\%) (Table 3). The common neurological sequelae were as follows: cranial nerve abnormalities were seen in 50 patients, which accounted for $22.4 \%$ of the population overall and $45.9 \%$ of patients with neurological sequelae. Among patients with cranial nerve abnormalities, 38 (76\%) had facial nerve deficits, 9 (18\%) had oculomotor problems, and $3(6 \%)$ had optic nerve deficits.

Forty-one patients presented with right-sided hemiparesis following injury, accounting for $41.4 \%$ of patients with neurological abnormalities and $18.4 \%$ of the total number of patients with penetrating TBI. Thirty-six patients $(16.1 \%)$ presented with left-sided hemiparesis. Upper-limb monoparesis/monoplegia was noted in 5 (2.2\%) of the 223 patients, lower-limb monoparesis/monoplegia occurred in $4(1.8 \%)$ of the 223 patients. Nine $(4.0 \%)$ of the 223 patients presented with convulsions (Table 3 ).

\section{Associations Concerning the Mechanism of Injury}

Neurological sequelae following gunshot and stab injuries were present in $63(49.6 \%)$ and $46(47.9 \%)$ patients, respectively (Table 4). The neurological abnormality profiles for the two types of mechanisms were fairly similar without a statistically significant difference (chi-square $4.245, \mathrm{p}=0.751)$.

\section{Mechanism of Injury and Side of Entry Wound}

Stab wounds occurred more on the left side, while gunshot wounds occurred more on the right side (Table 5). Left-sided injuries were seen in $56(58.3 \%)$ of the 96 patients with stab injuries, while right-sided injuries oc-

TABLE 2. Mechanism of injury versus age*

\begin{tabular}{lcccc}
\hline & \multicolumn{3}{c}{ Age in Yrs } & \\
\cline { 2 - 4 } Mechanism & $0-2$ & $3-12$ & $13-16$ & Total \\
\hline Stab wound & 18 & 53 & 56 & 127 \\
\hline Gunshot & 31 & 83 & 109 & 273 \\
\hline
\end{tabular}

* There was no statistically significant relationship between age and mechanism of injury (chi-square $3.011, p=0.222$ ). 
TABLE 3. Neurological abnormalities as percentages of the total number of patients

\begin{tabular}{lc}
\hline Neurological Abnormality & Percentage of Patients \\
\hline Cranial nerve deficit & 22.4 \\
\hline Rt hemiparesis & 18.4 \\
\hline Lt hemiparesis & 16.1 \\
\hline Convulsions & 4.0 \\
\hline Blindness & 3.6 \\
\hline Aphasia/dysphasia & 3.1 \\
\hline Monoparesis, upper limbs & 2.2 \\
\hline Monoparesis, lower limbs & 1.8 \\
\hline Cerebellar signs & 0.4 \\
\hline
\end{tabular}

curred in 40 (42.7\%). Forty-nine (38.6\%) of the 127 patients with gunshot injuries had left-sided entry wounds, whereas right-sided entry wounds were seen in 78 (61.4\%) of these patients. The odds ratio (number left/number right) for stab wounds versus gunshot entry wounds is 2.2. There was a statistically significant relationship between the mechanism of injury and the side of penetration (chisquare $8.56, \mathrm{p}=0.003$ ).

\section{Mechanism of Injury Versus Sex and Age}

There was no statistically significant relationship between mechanism of injury and sex (chi-square 1.87, $\mathrm{p}=$ 0.171 ). There was no difference between the mean ages for the two mechanisms of injury when tested with the Mann-Whitney U-test $(\mathrm{Z}=-1.17, \mathrm{p}=0.242)$-for gunshot injuries $(n=127)$, the mean rank was 107.64 and the sum of ranks was 13,670.00; for stab injuries $(\mathrm{n}=96)$, the mean rank was 117.77 and sum of ranks was 11,306.00 (total number of patients $=223, \mathrm{Z}=-1.17, \mathrm{p}=0.242$ ).

\section{Mechanism of Injury Versus GCS Score}

There was a statistically significant correlation between

TABLE 4. Neurological abnormalities as percentages per mechanism of injury*

\begin{tabular}{lcccccc}
\hline & \multicolumn{2}{c}{ Gunshot } & & \multicolumn{2}{c}{ Stab } \\
\cline { 2 - 3 } \cline { 5 - 6 } Neurological Abnormality & $\begin{array}{c}\text { No. of } \\
\text { Patients }\end{array}$ & $\%$ & & $\begin{array}{c}\text { No. of } \\
\text { Patients }\end{array}$ & $\%$ \\
\hline Cranial nerve deficit & 27 & 21.3 & & 23 & 24.0 \\
\hline Rt hemiparesis & 24 & 18.9 & & 12 & 12.5 \\
\hline Lt hemiparesis & 25 & 19.7 & & 16 & 16.7 \\
\hline Convulsions & 4 & 3.1 & 5 & 5.2 \\
\hline Blindness & 4 & 3.1 & 4 & 4.2 \\
\hline Aphasia/dysphasia & 4 & 3.1 & 3 & 3.1 \\
\hline Monoparesis, upper limbs & 3 & 2.4 & 2 & 2.1 \\
\hline Monoparesis, lower limbs & 3 & 0.8 & 3 & 3.1 \\
\hline Cerebellar signs & 1 & 0.8 & 0 & 0 \\
\hline
\end{tabular}

* The neurological abnormality profiles for the two mechanisms were similar (chi-square 4.245, $p=0.751$ ).
TABLE 5. Mechanism of injury and side of entry wound*

\begin{tabular}{cccc}
\hline \multirow{2}{*}{$\begin{array}{c}\text { Mechanism } \\
\text { of Injury }\end{array}$} & \multicolumn{2}{c}{ No. of Patients } & \\
\cline { 2 - 3 } & Lt Side & Rt Side & Total \\
\hline Gunshot & 49 & 78 & 127 \\
\hline Stab & 56 & 40 & 96 \\
\hline Total & 105 & 118 & 223 \\
\hline
\end{tabular}

* Stab wounds occurred more frequently on the left side, whereas gunshot wounds occurred more on the right side (chi-square 8.56; $p=0.003$ ). The odds ratio (number left/number right) for stab wounds versus gunshot wounds was 2.2 .

mechanism of injury and the GCS score. For patients with GCS scores of 3-8 and 9-12, the percentages of gunshot injury wounds was higher $(66 \%$ and $74 \%$, respectively; chi-square $12.170, \mathrm{p}=0.002$ ) (Table 6). For patients with GCS scores of 13-15, the percentage of gunshot wounds was slightly less than that for stab injuries ( $48 \%$ vs $52 \%$ ). This was not statistically significant.

\section{Mechanism of Injury and Side of Entry Wound Versus GCS Score}

The relationship between mechanism of injury and side of entry wound versus GCS score was significant for the left-sided entry wounds (chi-square 5.977, $\mathrm{p}=0.050$ ) (Table 7). For the right-side entry wounds, this relationship was only slightly less correlated (chi-square 5.969, p $=0.051$ ). For each side of the entry wound (left or right side), in patients with GCS score of 13-15, the proportion of patients with stab injuries was significantly higher than for the patients in the other two groups of GCS scores.

\section{Neurological Sequelae Versus No Sequelae}

In a comparison of characteristics of patients in whom no neurological sequelae were recorded with those of patients in whom at least 1 deficit was recorded, we observed the following: 1) The mean age for the patients with no neurological sequelae was significantly lower than that for patients with 1 or more neurological sequelae (MannWhitney U-test: $\mathrm{Z}=-3.428, \mathrm{p}=0.001)$. The mean age of patients with no neurological sequelae was 8.96 years whereas the mean age for those with 1 or more neurological sequela was 11.72 years. 2) The mean duration of hospitalization for the patients with no neurological sequelae (8.22 days) was not significantly different from that for

TABLE 6. Mechanism of injury versus GCS score*

\begin{tabular}{cccc}
\hline GCS Score & Gunshot & Stab & Total \\
\hline $3-8$ & 23 & 12 & 35 \\
\hline $9-12$ & 40 & 40 & 54 \\
\hline $13-15$ & 64 & 70 & 134 \\
\hline Total & 127 & 96 & 223 \\
\hline
\end{tabular}

* For patients with GCS scores of 3-8 and 9-12, the percentages of gunshot wounds were higher than they were for patients with lower GCS scores $(66 \%$ vs $74 \%$, respectively; chi-square $12.170, p=0.002$ ). 
TABLE 7. Mechanism of injury and side of entry wound versus GCS score*

\begin{tabular}{cccc}
\hline Side of Entry, GCS Score & Gunshot & Stab & Total \\
\hline Lt side & & & \\
\hline $3-8$ & 7 & 6 & 13 \\
\hline $9-12$ & 17 & 9 & 26 \\
\hline $13-15$ & 25 & 41 & 66 \\
\hline Total & 49 & 56 & 105 \\
\hline Rt side & & & \\
\hline $3-8$ & 16 & 6 & 22 \\
\hline $9-12$ & 23 & 5 & 28 \\
\hline $13-15$ & 39 & 29 & 68 \\
\hline Total & 73 & 40 & 118 \\
\hline
\end{tabular}

* For left-side injuries: chi-square $5.977, p=0.050$. For right-side injuries: chi-square 5.969, $p=0.051$.

patients with 1 or more neurological sequela (8.39 days) (Mann-Whitney U-test: $Z=-0.054, p=0.957$ ). 3) When sex differences were compared between patients with and without neurological dysfunction, no statistically significant difference was observed (chi-square $0.053, \mathrm{p}=0.818$ ). 4) The proportion of patients with gunshot and stab wound injuries in whom neurological sequelae were present versus absent was not significantly different (chi-square $0.062, p=0.803) .5$ ) The proportion of patients with leftand right-sided entry wounds (side of penetration) associated with the presence versus absence of neurological sequelae was also not significantly different (chi-square $2.014, \mathrm{p}=0.153)$.

A logistic regression was performed with neurological sequelae ( 0 for none, 1 for one or more) as response variable and age, hospital duration, sex, mechanism of injury (gunshot or stab), and side of entry wound (left or right) as explanatory variables. Only age turned out to be significant at the 5\% level, which confirms the results set out under points $1-5$ above.

\section{Convulsions Versus Side of Entry Wound}

The proportion of patients with convulsions (Table 8) that followed a left-sided entry wound was significantly higher than the proportion of patients with convulsions that followed a right-sided entry wound (odds ratio 4.14, in favor of left side vs the right).

TABLE 8. Convulsion versus side of entry wound*

\begin{tabular}{cccc}
\hline & \multicolumn{2}{c}{ Convulsions } & \\
\cline { 2 - 3 } Side of Entry Wound & No & Yes & Total \\
\hline Rt & 98 & 7 & 105 \\
\hline Lt & 116 & 2 & 118 \\
\hline Total & 214 & 9 & 223 \\
\hline
\end{tabular}

* The odds ratio (number yes/number no) for the left-sided versus right-sided entry wounds was 4.14 .
TABLE 9. Convulsions versus mechanism of injury and side of entry wound*

\begin{tabular}{cccc}
\hline \multirow{2}{*}{$\begin{array}{c}\text { Mechanism of } \\
\text { Injury }\end{array}$} & \multicolumn{2}{c}{ Convulsions } & \\
\cline { 2 - 3 } & No & Yes & Total \\
\hline Gunshot & & & \\
\hline Rt side & 47 & 2 & 49 \\
\hline Lt side & 76 & 2 & 78 \\
\hline Total & 123 & 4 & 127 \\
\hline Stab & & & \\
\hline Rt side & 51 & 5 & 56 \\
\hline Lt side & 40 & 0 & 40 \\
\hline Total & 91 & 5 & 96 \\
\hline
\end{tabular}

* For gunshot wounds: chi-square $0.227, p=0.634$. For stab wounds: chisquare $3.768, p=0.052$.

\section{Convulsions Versus Mechanism of Injury and Side of Entry Wound}

For gunshot wounds, there was no statistically significant relationship between convulsions and the side of the entry wound (chi-square $0.227, \mathrm{p}=0.634$ ) (Table 9). For stab wounds, the proportion of patients with convulsions that occurred in those with a left-sided entry wound was significantly higher than it was for those with a right-sided entry wound (chi-square 3.768 , $\mathrm{p}$ value $=0.052$ ).

Of the 96 patients with stab wounds, $5(5.2 \%)$ presented with seizures and had left-sided injuries. Only 4 of the 127 patients with gunshot injuries presented with seizures and only 2 of these had left-sided gunshot injuries. Among patients with gunshot injuries, $2(4.1 \%)$ of the 51 with leftsided injuries presented with seizures compared with 2 $(2.56 \%)$ of the 78 patients with right-sided injuries. For patients with stab head injuries, $5(9.8 \%)$ of the 51 patients with left-sided wounds presented with seizures, whereas no seizures where observed in the 40 patients with rightsided stab injuries.

\section{Associations Concerning Sequelae}

Frequencies of Types of Neurological Sequelae

Of neurological abnormalities that occurred as a single or isolated sequela, right-sided hemiparesis was the most common, followed by left-sided hemiparesis and then by cranial nerve deficits. Where 2 or more neurological deficits occurred together, a combination of cranial nerve deficits and right- or left-sided hemiparesis was the most frequent pairing.

\section{Discussion}

\section{Perspective}

All the pediatric patients included in this study were seen following penetrating head injury at the only public neurosurgical department in the province of KwaZuluNatal, South Africa, between the years 1985 and 2007. During this period, 18,982 patients with head injury were admitted to the neurosurgery department. Of these, 3020 were children under 16 years of age and 223 had sustained 
a penetrating head injury. Pediatric penetrating head injuries accounted for $7.38 \%$ of all pediatric head injury admissions in children under 16 years of age and $1.18 \%$ of the total number of head trauma admissions to the neurological service. Penetrating head injuries were divided into those caused by gunshots and those caused by stabbings. The exact incidence of penetrating head injury in the pediatric population is not known. ${ }^{18,20}$

The pathophysiological mechanisms in gunshot injuries involve energy translation, tissue cavitation, and shockwave formation. ${ }^{11}$ The mortality rate from gunshot injuries may be as high as 50\%.11,22 The goal of surgical intervention in patients with penetrating TBI is to reduce mass effect from the necrotic tissue and contused brain and from intracranial hematomas. ${ }^{11}$ The principles in surgical management of penetrating head injury include early debridement, removal of foreign body material, and evacuation of intracranial hematomas, as well as reduction of brain edema. ${ }^{6,8,9}$ Stab injuries accounted for $57 \%$ of our patients while gunshot wounds were seen in $43 \%$ of these patients.

\section{Age Groups at Risk}

The age groups under study were divided into three ranges: $0-2$ years, $3-12$ years, and $13-16$ years. The 13 - to 16-year-old patients were slightly more vulnerable to penetrating head injuries. This may be attributed to greater interpersonal violence. The younger age groups are often injured indirectly, either due to child abuse or as a shielding injury, and often the forces involved tend to be less severe than in adults. ${ }^{12,14,19}$ It is worth mentioning that in some cases, circumstances of injury were not clear.

\section{Sex}

As in earlier studies from South Africa, ${ }^{10,11,19}$ stabs to the head constitute a significant mechanism of injury. Males still constituted the majority of the patients (84.8\%) compared with females (15.2\%). Both of the mechanisms of injury (stabbing and shooting) affected children of all ages irrespective of the age group.

\section{Neurological Manifestations}

Neurological sequelae at admission were considered and included cranial nerve deficits, hemiparesis (left or right side), aphasia or dysphasia, blindness, cerebellar ataxia, and seizures. For the purposes of this study, the GCS score was discussed separately and not under neurological abnormalities.

A similar pattern of neurological abnormalities following penetrating head injuries was observed in other studies. ${ }^{16,17}$ In the study by Hagan ${ }^{16}$ right-sided hemiparesis/ hemiplegia was the most common anomaly. Left-sided hemiplegia, aphasia, and visual abnormalities, although less common, were also noted.

As in previous studies, ${ }^{17}$ the seventh cranial nerve was the most commonly affected $(76 \%)$ cranial nerve in this study. Nine of the patients had third cranial nerve abnormalities, and optic nerve abnormalities were seen in $6 \%$ of the patients with cranial nerve abnormalities. Unlike findings in other studies, ${ }^{17}$ none of our patients had fifth cranial nerve abnormalities. This could be attributed to the difficulties of evaluating the fifth cranial nerve in pediatric patients. The number of patients with neurological sequelae at admission was $109(48.9 \%)$, a rate that is lower than the $69 \%$ reported in the study by Hagan. ${ }^{16}$

Stab injuries were present in $5(2.2 \%)$ of the patients with seizures while gunshot injuries were demonstrated in $4(1.8 \%)$. In the present study, the patients in the older age groups (mean age 11.72 years) were more likely to present with neurological abnormalities than those who were younger (mean age 8.96 years), a finding that is similar to earlier studies that point to the fact that older patients are prone to these deficits. 4,5

\section{Convulsions}

Posttraumatic seizures are classified as immediate if they occur within 24 hours of injury, early if they occur within 1 week of injury, and late if they occur after 1 week of injury. ${ }^{24}$ Among the 223 patients seen in this study, 9 (4.04\%) presented with seizures following penetrating head injury. These patients presented within 24 hours of injury, and so the seizures were mainly of the immediate type. Although phenytoin and valproate can reduce the incidence of early-onset seizures, they have not been shown to prevent the onset of late seizures in patients with TBI. ${ }^{11,15}$ Four (3.15\%) of the 127 patients with gunshot injuries presented with seizures, while $5(5.1 \%)$ of 96 patients with stab injuries presented with posttraumatic seizures. Besides the intracranial hematomas and contusions, the patients in our study also presented with skull fractures, and metal and bone fragments were also retained in gunshot injury patients. The factors placing patients at increased risk for seizures among the present patient population are similar to prognostic factors for seizures noted in other studies. ${ }^{25,28}$ In the stab injury patients with retained knife blades, the blades were removed at surgery. Previous studies have indicated the incidence of immediate posttraumatic seizures to range from $1 \%$ to $4 \%$ following head injury. ${ }^{4}$ Some studies have shown a higher frequency of seizures (50\%) following penetrating head injury. ${ }^{2}$

The risk factors for posttraumatic seizures have been documented to include a low GCS score, loss of consciousness, and posttraumatic amnesia lasting more than 24 hours, as well as intracranial hematomas. ${ }^{5}$ Various studies have documented significant confounding factors in posttraumatic seizures to include site of injury, particularly injury at the rolandic fissure.

Temkin ${ }^{27}$ reported an incidence of posttraumatic seizure of $25 \%$ in patients with depressed skull fractures and intracerebral and subdural hematomas. Besides these factors, the frequency of seizures was also found to be related to the site of injury, the patient age, number of affected lobes, intracranial hematoma, retained metallic or bone fragments, and projectile type. ${ }^{27}$

It is not clear why the gunshot injuries did not result in more patients presenting with seizures than those with stab wound injuries. However, since many of these stab wounds were left sided, it is likely that most of the injuries were inflicted by right-handed assailants. In our patients, the frequency of posttraumatic seizures could not be linked to the involvement of the mesial temporal struc- 
tures. The increased frequency of seizures among patients with stab injuries, particularly on the left side, could be due to the predominance of combined frontotemporal hematomas/contusions. Various studies have shown a significant relationship between the number of lobes involved and seizures. ${ }^{28}$ Almost all of our patients with stab injuries had lesions in the left frontotemporal regions, with associated hematomas along the tract of injury. These lesions could explain the higher frequency of seizures in these patients. As indicated, left-sided stab injuries accounted for $58.3 \%$ of the injuries, while right-sided gunshot injuries accounted for $42 \%$. A strong correlation between leftsided injuries and seizures was also noted in the study by Annegers and Coan. ${ }^{4}$

Because of poor record keeping prior to 2003 and the relocation of the neurosurgical unit from the Wentworth Hospital to the Inkosi Albert Luthuli Central Hospital, we had to rely solely on the scan reports and so a clear and defined description of the scans may be lacking in this study. The descriptive pattern of the number of lobes involved in gunshot injuries in our study was also not clear and we could not draw concise deductions from the available records.

The association between left-sided stab injuries and convulsions may relate to a supposition that more force is involved in causing the left-sided injuries as most of the assailants were right handed. No long-term follow-up was done to determine the frequency and duration of late-onset seizures.

\section{Associations of Neurological Sequelae and the Mechanisms (Type) of Injury}

Civilian gunshot injuries are of the low-velocity type and so do not cause the extensive tissue destruction seen in war situations. ${ }^{7,21}$ Gunshot injuries cause tissue disruption by mechanisms of laceration, shock waves, and cavitation. ${ }^{7}$

The observations in the present study seem to reflect that the neurological sequelae are relatively similar in both mechanisms of penetrating head injury. However, one should bear in mind that besides the low-velocity gunshot injuries seen in this study, the distance of the victim from the assailant is not known and it is likely most of the pediatric gunshot injuries were accidental and not at close range. Low-velocity missile injuries are of less than 2500 feet per second. ${ }^{1}$ A qualifier is that only survivors are referred to the neurosurgical service, and the mortality rates are not well documented.

\section{Mechanism of Injury and Side of Entry Wound}

This study demonstrates that most stab injuries to the head were on the left side. This is explained by the fact that because most individuals are right handed, the victims are likely to sustain left-sided head injuries. An explanation for why more gunshot injuries occurred more frequently on the right side is difficult to establish.

\section{Mechanism of Injury and Sex}

Both mechanisms of penetrating head injury affected more males than females. Various studies have shown that males are affected more often than females. ${ }^{11,14}$ The rea- sons why this was similar in children may be entirely different.

\section{Mechanism of Injury and Admission GCS Score}

As illustrated in previous South African studies, stab injuries are a predominant cause of penetrating head injury in our population..$^{10,11}$

Gunshot injuries cause severe tissue disruption and so would account for the majority of those seen in individuals with low GCS scores..$^{19}$ Most of our patients had a GCS score greater than 9; this is in contrast to war situations, where the majority of gunshot injuries are of high velocity and often result in low GCS scores. It is worth noting that the strict admission criteria to our service leave out many severely injured patients who often have low GCS scores.

\section{Association Between the Mechanism of Injury and the Side of Entry Wound Versus the GCS Score}

There was a statistically significant correlation between the mechanism of injury and the side of entry wound versus the GCS score. The proportion of patients with stab injuries was significantly higher irrespective of the side of injury, particularly in those with a GCS score of 13-15. The majority of the patients with stab wounds remained stable with a GCS score of 13-15 unlike patients with gunshot injuries. This may be due to the focal nature of stab injuries. The findings are similar to those in previous studies demonstrating that gunshot injuries are of high velocity and result in more severe injury. ${ }^{6-8}$

\section{Neurological Sequelae}

The mean age of patients with no neurological sequelae at admission was 8.96 years, and this is significantly lower than the mean age (11.72 years) of those who presented with neurological sequelae. We observed that the younger the patients, the less likely they were to have neurological sequelae following penetrating head injury. This finding may be related to the fact that very young children are often injured accidentally during fights between family members and the force involved in inflicting the injury may be mild. ${ }^{14}$ Various studies have documented a positive correlation between advancing age and neurological sequelae such as seizures. ${ }^{4,5}$

This study showed that a female patient is likely to present with the same features as a male patient following penetrating head injury. The evaluation and detection of neurological abnormalities in children is difficult and challenging for the clinician.

\section{Convulsions Versus Mechanism of Injury and Side of Entry Wound}

The study showed that convulsions are strongly correlated to left-sided stab injuries; it is likely that most of the left-sided stabs were caused by right-handed assailants. The resulting force may have led to an increased predisposition to seizures due to hemispheric dominance. In our study, there was a predominance of left frontotemporal hematoma and contusions in patients who sustained a stab injury. Whereas various studies have reported a high incidence of seizures in patients with gunshot injuries, ${ }^{23,25-27,28}$ 
our study found an increased risk for seizures among patients with stab injuries compared with those with gunshot injuries. The reasons for this are not clear except for the left-sided hemispheric predominance among stab head injuries.

Various studies have documented an increased likelihood for seizures in patients with depressed skull fractures, intracranial hematomas, and a history of loss of consciousness, posttraumatic amnesia exceeding 24 hours, and age greater than 65 years after TBI., ${ }^{4,5,22}$

Unlike previous studies, which have reported the risk factors for posttraumatic seizures to be a history of loss of consciousness and posttraumatic amnesia, ${ }^{4,5}$ ours did not examine these parameters but rather focused on the side of the injury and mechanism of injury.

\section{Evolution in Management Over the 23-Year Period}

Management of patients with penetrating head injury over the 23-year period that the study covers has evolved from that of delayed to early and aggressive surgical intervention within 1-3 hours of arrival at the unit. This is significant when compared with surgical intervention, especially for debridement that would previously be delayed up to 24 hours.

Postoperatively the patients with intracranial hematomas, contusions, and brain edema are admitted to the intensive care unit and managed with sedation, ventilation, and intracranial pressure monitoring. This protocol was not necessarily the case previously. The current management strategies have greatly reduced the morbidity rate and enhanced early rehabilitation therapy.

Since the introduction of the electronic record keeping system after 2003 when the neurosurgical unit moved from the Wentworth Hospital to the Inkosi Albert Luthuli Central Hospital, the patient records and scans are now properly and sequentially stored and are easier to retrieve when needed. The new management philosophy also involves early angiographic studies (CT angiography) in patients with a stab injury to rule out vascular injury.

\section{Limitations to the Study}

As this was a retrospective study, there was no control over the management of the patients, and all patients admitted to the neurological surgery department are referred from a base hospital; thus, there is no direct control of the quality of resuscitation carried out at the base hospital. The quality of data was an additional limiting factor as some files contained incomplete documentation and other files were missing. Finally, because our unit is located in a tertiary hospital, many patients may have died before being referred to our unit. Some information may also not have been conveyed to our unit during the referral of the patient, and thus, there is an element of inclusion or selection bias. Due to limited resources, the strict admission criteria of our unit exclude many patients with penetrating head injuries with a very low GCS score and poor prognosis.

\section{Conclusions}

Penetrating head injuries in children are not as uncommon as previously thought. There was no correlation be- tween the age group of the patients and the mechanism of injury, which implies that stab or gunshot injuries could occur in any of our pediatric population with the same frequency. While gunshot injuries accounted for $56 \%$ of the patient population, stab injuries still accounted for $44 \%$.

Following penetrating head injuries, neurological abnormalities tend to occur in the older subgroup of the pediatric patients. The most common neurological abnormalities were hemiparesis followed by cranial nerve deficits. Facial nerve deficits were the most commonly seen cranial nerve abnormality. Immediate convulsions were a significant feature in patients with stab injuries to the head compared to those with gunshot injuries.

\section{Acknowledgments}

This study was performed as part of the MMed neurosurgery research, during specialist training in neurosurgery, the degree being awarded to the principal author (K.D.M.) by the University of KwaZulu-Natal in 2012.

\section{References}

1. Aarabi B: Traumatic aneurysms of brain due to high velocity missile head wounds. Neurosurgery 22:1056-1063, 1988

2. Adelson PD, Bratton SL, Carney NA, Chesnut RM, du Coudray HE, Goldstein B, et al: Guidelines for the acute medical management of severe traumatic brain injury in infants, children, and adolescents. Chapter 16. The use of corticosteroids in the treatment of severe pediatric traumatic brain injury. Pediatr Crit Care Med 4 (3 Suppl):S60-S64, 2003

3. Amirjamshidi A, Abbassioun K, Roosbeh H: Air-gun pellet injuries to the head and neck. Surg Neurol 47:331-338, 1997

4. Annegers JF, Coan SP: The risks of epilepsy after traumatic brain injury. Seizure 9:453-457, 2000

5. Annegers JF, Hauser WA, Coan SP, Rocca WA: A population-based study of seizures after traumatic brain injuries. $\mathbf{N}$ Engl J Med 338:20-24, 1998

6. Ascroft PB: Treatment of head wounds due to missiles: analysis of 500 cases. Lancet 2:211-218, 1943

7. Brandvold B, Levi L, Feinsod M, George ED: Penetrating craniocerebral injuries in the Israeli involvement in the Lebanese conflict, 1982-1985. Analysis of a less aggressive surgical approach. J Neurosurg 72:15-21, 1990

8. Campbell EH Jr: Compound comminuted skull fractures produced by missiles: report based upon 100 cases. Ann Surg 122:375-397, 1945

9. Cushing H: A study of a series of wounds involving the brain and the enveloping structures. Br J Surg 5:558-684, 1918

10. Domingo Z, Peter JC, de Villiers JC: Low-velocity penetrating craniocerebral injury in childhood. Pediatr Neurosurg 21:45-49, 1994

11. du Trevou MD, van Dellen JR: Penetrating stab wounds to the brain: the timing of angiography in patients presenting with the weapon already removed. Neurosurgery 31:905912,1992

12. Dujovny M, Osgood CP, Maroon JC, Jannetta PJ: Penetrating intracranial foreign bodies in children. J Trauma 15:981986, 1975

13. Dutcher S, Sood S, Ham S, Canady A: Skull fractures and penetrating brain injury, in McLone DG (ed): Pediatric Neurosurgery: Surgery of the Developing Nervous System, ed 4. Philadelphia: WB Saunders, 2001, 99 573-583

14. Fieggen AG, Wiemann M, Brown C, van As AB, Swingler GH, Peter JC: Inhuman shields-children caught in the crossfire of domestic violence. S Afr Med J 94:293-296, 2004

15. Glötzner FL, Haubitz I, Miltner F, Kapp G, Pflughaupt KW: 
[Seizure prevention using carbamazepine following severe brain injuries.] Neurochirurgia (Stuttg) 26:66-79, 1983 (Ger)

16. Hagan RE: Early complications following penetrating wounds of the brain. J Neurosurg 34:132-141, 1971

17. Haworth CS, de Villiers JC: Stab wounds to the temporal fossa. Neurosurgery 23:431-435, 1988

18. Hennes H, Lee M, Smith D, Sty JR, Losek J: Clinical predictors of severe head trauma in children. Am J Dis Child 142:1045-1047, 1988

19. Kieck CF, de Villiers JC: Vascular lesions due to transcranial stab wounds. J Neurosurg 60:42-46, 1984

20. Koestler J, Keshavarz R: Penetrating head injury in children: a case report and review of the literature. J Emerg Med 21:145-150, 2001

21. Kraus JF, Fife D, Cox P, Ramstein K, Conroy C: Incidence, severity, and external causes of pediatric brain injury. Am J Dis Child 140:687-693, 1986

22. Kumar A, Singh H, Sharma KC: Penetrating head injury from a pedestal fan rotor blade in a child-an unusual case. Pediatr Neurosurg 42:391-394, 2006

23. Martin J, Campbell EH Jr: Early complications following penetrating wounds of the skull. J Neurosurg 3:58-73, 1946

24. Rish BL, Caveness WF: Relation of prophylactic medication to the occurrence of early seizures following craniocerebral trauma. J Neurosurg 38:155-158, 1973

25. Salazar AM, Jabbari B, Vance SC, Grafman J, Amin D, Dillon JD: Epilepsy after penetrating head injury. I. Clinical correlates: a report of the Vietnam Head Injury Study. Neurology 35:1406-1414, 1985

26. Swanson SJ, Rao SM, Grafman J, Salazar AM, Kraft J: The relationship between seizure subtype and interictal personality. Results from the Vietnam Head Injury Study. Brain 118:91-103, 1995

27. Temkin NR: Risk factors for posttraumatic seizures in adults. Epilepsia 44 (Suppl 10):18-20, 2003

28. Weiss GH, Salazar AM, Vance SC, Grafman JH, Jabbari B: Predicting posttraumatic epilepsy in penetrating head injury. Arch Neurol 43:771-773, 1986

\section{Disclosures}

The authors report no conflict of interest concerning the materials or methods used in this study or the findings specified in this paper.

\section{Author Contributions}

Conception and design: Muballe. Acquisition of data: Muballe. Analysis and interpretation of data: Muballe. Drafting the article: Muballe. Critically revising the article: Muballe. Reviewed submitted version of manuscript: Hardcastle. Approved the final version of the manuscript on behalf of all authors: Muballe. Statistical analysis: Muballe. Study supervision: Kiratu.

\section{Correspondence}

Kadhaya David Muballe, Department of Neurosurgery, University of Kwa Zulu Natal, 800 Vusi Mzimela Rd., Mayville, Durban, KwaZulu-Natal 4091, South Africa. email: kmuballe@yahoo. co.uk. 